\title{
An Examination of the Effect of Continuous Quality Improvements on Optimal Pricing for Durable Goods*
}

\author{
Ram Narasimhan \\ Department of Management, The Eli Broad Graduate School of Business, \\ Michigan State University, East Lansing, MI 48824-1122, e-mail: narasimh@pilot.msu.edu \\ David Mendez \\ Department of Health Management and Policy, School of Public Health, \\ The University of Michigan, Ann Arbor, MI 48109, e-mail: dmendez@umich.edu \\ Soumen Ghosh \\ Georgia Institute of Technology, School of Management, Atlanta, GA 30332-0520, \\ e-mail: soumen.ghosh@mgt.gatech.edu
}

\section{ABSTRACT}

This paper investigates the nature of optimal prices for a durable good in the presence of continuous quality improvements. The analysis of optimal prices is based on a nonlinear dynamic model of sales response that relates price, quality, average life of a product and the persistence of quality perceptions. Numerical solutions to the model are derived by employing the generalized reduced gradient algorithm. The results show that optimal price depends on the persistence of quality perceptions and the average life of a product (an aspect of quality). The analysis of optimal results affirms results based on other models and provides insights on the influence that quality has on optimal pricing. The implications of the results and suggestions for future research are discussed.

Subject Areas: Dynamic Optimization, Price, Quality, and Sales Response.

\section{INTRODUCTION}

This paper investigates the optimal pricing decision for a durable good in the presence of continuous quality improvements. It is assumed that the durable goods manufacturer wants to maximize discounted profits over a specified planning horizon. The investigation of optimal prices is carried out using the model proposed by Narasimhan, Ghosh, and Mendez [28], who analyzed the effect that the dynamic interactions of price and quality have on the sales rate of a durable good. The authors showed that the average life of a product (an aspect of quality) and the persistence

*The authors wish to acknowledge the insightful comments and thoughtful criticisms of an associate editor and four anonymous reviewers. Their comments have significantly improved the content and clarity of the paper. 
of quality perceptions both interact in important ways to determine the sales rate. They demonstrated that incorporating these aspects of quality in a sales response model makes it possible to capture the evolution of sales over time better than a diffusion model that does not incorporate product quality. The authors demonstrated the conceptual validity of the model by comparing the model generated sales to actual sales data. However, the model was not used to develop optimal pricing strategies for a durable good.

Although the issue of optimal pricing has received a lot of attention in the marketing literature, there is a paucity of research papers that incorporate the effects of product quality on optimal pricing, in spite of the general agreement among practitioners and researchers alike that product quality plays a critical role in a firm's ability to compete successfully. Recent literature, however, has tended to focus on the interrelationships among pricing, quality, the sales process and competition. The relationship between quality and pricing affects the sales response for a durable good in important ways.

This paper extends existing literature by attempting to study the behavior of optimal prices in the presence of continuous quality improvements. An optimal control model is used to maximize discounted profits at a specified target time and to analyze the effect of price-quality interactions on the sales rate of a product. The sales response is modeled as a function of the price elasticity of demand, life of the product (durability), the market sensitivity to quality improvements, and the persistence delay associated with quality perceptions. We also investigate the effect of terminal time (i.e., short-term versus long-term orientation) on the optimal pricing strategies. The results of experimentation with the model indicate that there is a definite relationship between optimal prices and product quality. The direction and strength of the relationship is dependent on the average life of the product and the diffusion process associated with quality improvements. This result differs from studies found in the marketing literature that have concluded that the relationship between price and quality is either weak or nonexistent [13] [26]. The results also show that the ratio of average life of product to the persistence of quality perceptions seems to play an important role in the behavior of optimal price trajectories. This result may be important in the determination of promotion and advertising strategies for the product.

\section{RELATED LITERATURE}

The relationship between product quality and pricing as a determinant of sales has been receiving some attention in the literature. Tapiero, Ritchken, and Reisman [38], propose a framework for examining the tradeoffs among product pricing, reliability, design, and quality control issues. The authors used a "risk management" approach to compare alternative quality control schemes and pricing under stochastic demand. Since the authors investigated substitution effects of quality and pricing given the desired degree of risk aversion, they concluded that lower prices can substitute for outgoing quality. The authors address quality from an operational perspective. Banker and Khosla [2] consider oligopolistic competition in a model that investigates whether equilibrium levels of quality increase as competition intensifies. The authors do not explicitly consider the dynamic interaction between quality and sales 
response. Lee and Tapiero [21] assess the effects of quality control on sales. Given a set of "sales parameters," the authors show what the effects will be on quality control.

Another stream of research in the literature investigates price-quality relationship. The main focus of these papers is the investigation of the presumed positive relationship between price and quality, and higher price as a signal of higher quality. Monroe and Dodds [26], provide an excellent review and assessment of marketing literature dealing with this topic. The authors conclude that investigation of pricequality relationship is incomplete and suggest that the dynamic relationship between price and quality merits a richer conceptualization. Rao and Monroe [32] have conducted a meta-analysis of experimental studies in marketing to examine the relationship between price and perceptions of product quality. Their study concluded that there is a positive, statistically significant relationship between price and perceived quality. Dodds, Monroe, and Grewal [9] have studied the effect of price on product evaluations by customers, including perceived quality. The authors used a designed experiment to pursue their investigation. Gerstner [13] empirically investigated the relationship between price and quality and concluded that the relationship was weak. The author did not explore the effect of price-quality relationship on the sales response of products. Additional examples of this implicit, and indeed, implied relationship between price (as a signal of quality) and quality can be found in McClure and Spector [24], Besanko and Winston [5] and Bagwell and Riordon [4].

The literature on optimal pricing for a profit maximizing firm is extensive. Mesak [25] has discussed the optimal strategic pricing of technological innovations. Kohli and Mahajan [19] discussed a conjoint analysis approach to examining pricing decisions for new products. Cook [7] presented a framework for pricing to maximize profit, taking into consideration price elasticity of demand in the telecommunications industry. Investigations into optimal pricing decisions include Robinson and Lakhani [33], Dolan and Jeuland [10], Khalish [16] [17], Narasimhan and Mendez [29], Thompson and Teng [39], and Dockner and Jorgensen [8]. Narasimhan and Ghosh [27] developed an optimal control model to study the effect of quality on optimal pricing and advertising decisions. The authors presented qualitative characterizations of the nature of optimal price and advertising policies.

Diffusion models that incorporate pricing stem from Bass' [3] model of new product diffusion. Mahajan, Muller, and Bass [22] present an excellent review of diffusion models and suggest new directions for research. Narasimhan, Ghosh, and Mendez [28] presented a dynamic model that included quality considerations in modeling the sales response for a product (referred to hereafter as the NGM model). The authors considered demand elasticity, quality, average life of a product, and the persistence of quality perceptions. The NGM model was shown to have conceptual validity in that the estimated parameter values accorded well with observed values and explained approximately $70 \%$ of the variation in actual sales data for a durable good. However, the authors did not derive any solutions based on their model.

In summary, although considerable research exists on optimal pricing, research dealing with the dynamic interaction among quality, optimal pricing and sales is scant, and the nature of the relationship is not fully understood. It is the aim of this paper to fill this research need. 
This paper uses the NGM model to investigate the optimal pricing decision. It differs from previous studies in that it explicitly models the dynamic relationship among quality, price and sales rate for a durable good. This paper also examines the effect of durability and the diffusion of quality improvements on sales and optimal prices.

In the following sections, we discuss the NGM model, the optimization approach that utilizes the generalized reduced gradient method, and numerical solutions to the model under various parameter settings.

\section{REFERENCE MODEL}

To set the stage for the ensuing discussion, the NGM model [28] is briefly reviewed (omitting the conceptual discussion that leads to the development of the model).

The full mathematical specification of the NGM model is:

$$
\begin{aligned}
& M\left(P_{t}\right)=\left(\frac{P_{0}}{P_{t}}\right)^{e} M_{0}, \\
& Q_{t}=D 1 \times Y_{t}, \\
& \frac{d}{d t} X_{t}=\frac{1}{D 2}\left(q_{t} \times S_{t}-X_{t}\right), \\
& \frac{d}{d t} Y_{t}=\frac{1}{D 1}\left(S_{t}-Y_{t}\right), \\
& E Q_{t}=D 2 \times X_{t} \\
& S_{t}=\alpha \times E Q_{t} \times\left(M_{P}-Q_{t}\right),
\end{aligned}
$$

where

$P_{t}=$ Price [\$],

$q_{t}=$ Quality index [0 to 1 ],

$M_{t}=$ Market potential [units],

$Q_{t}=$ Quantity of units in the market [units],

$S_{t}=$ Sales rate [units/time],

$Y_{t}=$ Rate at which units leave the market [units/time],

$X_{t}=$ Rate at which the quality-weighted quantity of goods in the market ceases to influence consumers' behavior [units/time],

$E Q_{\imath}=$ Quality weighted quantity of goods in the market [units],

$D 1=$ Average life of the units [time],

$D 2$ = Average time of the effect of quality of goods on consumer's buying behavior (quality persistence delay),

$\alpha=$ Proportionality constant used to calculate sales rate [time-units $]^{-1}$, and

$\boldsymbol{e}=$ Price elasticity of demand.

Price $(P)$ and quality $(q)$ are inputs to the model. The price level $(P)$ determines the market potential $(M)$ in (1) through a function similar to a demand function, 
parameterized by the product's elasticity of demand. The number of units currently in the market $(Q)$ is subtracted from the market potential $(M)$ to compute the number of units that can be potentially sold. The product of this quantity with the "quality weighted" units in the market $(E Q)$ generates the sales rate $(S)$ in $(6)$ according to a 'diffusion process' (see [3] and [28]). The computation of $E Q$ is accomplished by multiplying the sales rate $(S)$ by the quality level of the units $(q)$, and integrating the product $q \times S$ along a distributed delay (see [11], [24], and [28]) that represents the length of time that the quality of a unit continues to affect sales by influencing customer perceptions of quality, as shown in (3) and (5). The distributed delay is parameterized by the value $D 2$, which represents the average length of time during which the quality of a product influences new sales. Also, the sales rate is integrated within another delay that represents the life span of the product to compute the number of units currently in the market $(Q)$, as depicted in (2) and (4). This delay is parameterized by the value $D 1$, which represents the average life span of the product. Variables $Q$ and $E Q$ feed back into the diffusion equation that generates the sales rate function $(S)$ in $(6)$.

Given the state variables $X_{t}$ and $Y_{t}$, the differential equations corresponding to the state space representation of the model are:

$$
\frac{d X_{t}}{d t}=\alpha q_{t}\left(\frac{P_{0}}{P_{t}}\right)^{e} M_{0} X_{t}-\alpha D 1 q_{t} X_{t} Y_{t}-\frac{X_{t}}{D 2}
$$

and

$$
\frac{d Y_{t}}{d t}=\alpha \frac{D 2}{D 1}\left(\frac{P_{0}}{P_{t}}\right)^{e} M_{0} X_{t}-\alpha D 2 X_{t} Y_{t}-\frac{Y_{t}}{D 1}
$$

\section{PROBLEM STATEMENT AND SOLUTION METHOD}

\section{Problem Statement}

Given the formulation in (1) to (6), our objective is to compute $P_{[0, T]}^{*}$, that is, the optimal price trajectory that maximizes total discounted profits $(\Pi)$ at the specified target time $(T)$ :

$$
\Pi_{T}=\int_{0}^{T}\left(P_{t}-C_{t}\right) \times S_{t} \times \exp (-r t) d t
$$

where $C_{t}$ represents the unit cost at time $t$, and $r$ the discount rate. Using (1) to (6), the sales rate function $S_{t}$ can be expressed in terms of the state variables $X$ and $Y$; combining the expression for $\Pi_{T}$ with the state space representation of the model, given in (7) and (8), we arrive at the following optimal control formulation: 


$$
\operatorname{Max}_{P_{[0, \ldots]}, T} \Pi_{T}=\alpha D 2 \int_{0}^{T}\left(P_{t}-C_{t}\right)\left(\left(\frac{P_{0}}{P_{t}}\right)^{e} M_{0} X_{t}-D 1 X_{t} Y_{t}\right) \exp (-r t) d t
$$

subject to

$$
\begin{aligned}
& \frac{d X_{t}}{d t}=\alpha q_{t}\left(\frac{P_{0}}{P_{t}}\right)^{e} M_{0} X_{t}-\alpha D 1 q_{t} X_{t} Y_{t}-\frac{X_{t}}{D 2}, \\
& \frac{d Y_{t}}{d t}=\alpha \frac{D 2}{D 1}\left(\frac{P_{0}}{P_{t}}\right)^{e} M_{0} X_{t}-\alpha D 2 X_{t} Y_{t}-\frac{Y_{t}}{D 1},
\end{aligned}
$$

with the initial conditions:

$$
X_{0}=x 0, \quad Y_{0}=y 0 .
$$

To evaluate total discounted profits in the above objective function, we need to specify a functional form for the unit cost as quality changes over time. There is some controversy in the literature regarding the functional relationship between quality and cost. Plunkett and Dale [31] present empirical analysis of cost data that leaves the specification of cost as a function of quality inconclusive. The results of their study suggest that cost could increase as a function of quality. Other studies in the literature argue that cost decreases with increasing levels of quality (see, e.g., [36]).

In this paper, quality is viewed broadly to include its various aspects. Specifically, the conceptualization of quality in this paper encompasses the various dimensions of quality discussed by Garvin [12], and the dimensions "conformance quality" and "perceived quality" discussed by Buzzell and Gale [6]. Although conformance quality may not act as a price differentiator for some durable goods, it is reasonable to speculate that it does influence long-term dimensions of quality such as durability and reliability, which can act as price differentiators. It should be noted that conformance quality influences customer perceptions of the quality of a durable good over its life. Perceived quality is a price differentiator and a determinant of cost. As Buzzell and Gale point out, a firm must manage both conformance quality and perceived quality successfully, to achieve superior performance.

In the ensuing optimization scenario analyses, the composite measure of quality is varied from an initial value of 0.25 to a maximum attainable value of 1 . Accordingly, the cost function decreases as quality increases over a range and then reverses direction (due to increasing product diversity and complexity) as quality approaches a value of 1 . The cost function, shown in Table 1 , was constructed by assuming a $40 \%$ reduction in cost as quality increases from 0.25 to 0.9 , and a $40 \%$ increase as quality approaches the maximum value of 1 . The percentage change in cost of this magnitude is alluded to in [36] and was verified by the practitioner who was contacted by the authors. Figure 1 shows the relationship between quality level and the percentage change in unit cost. This figure was constructed by fitting a Lagrange interpolation polynomial [35] to the values in Table 1 . 


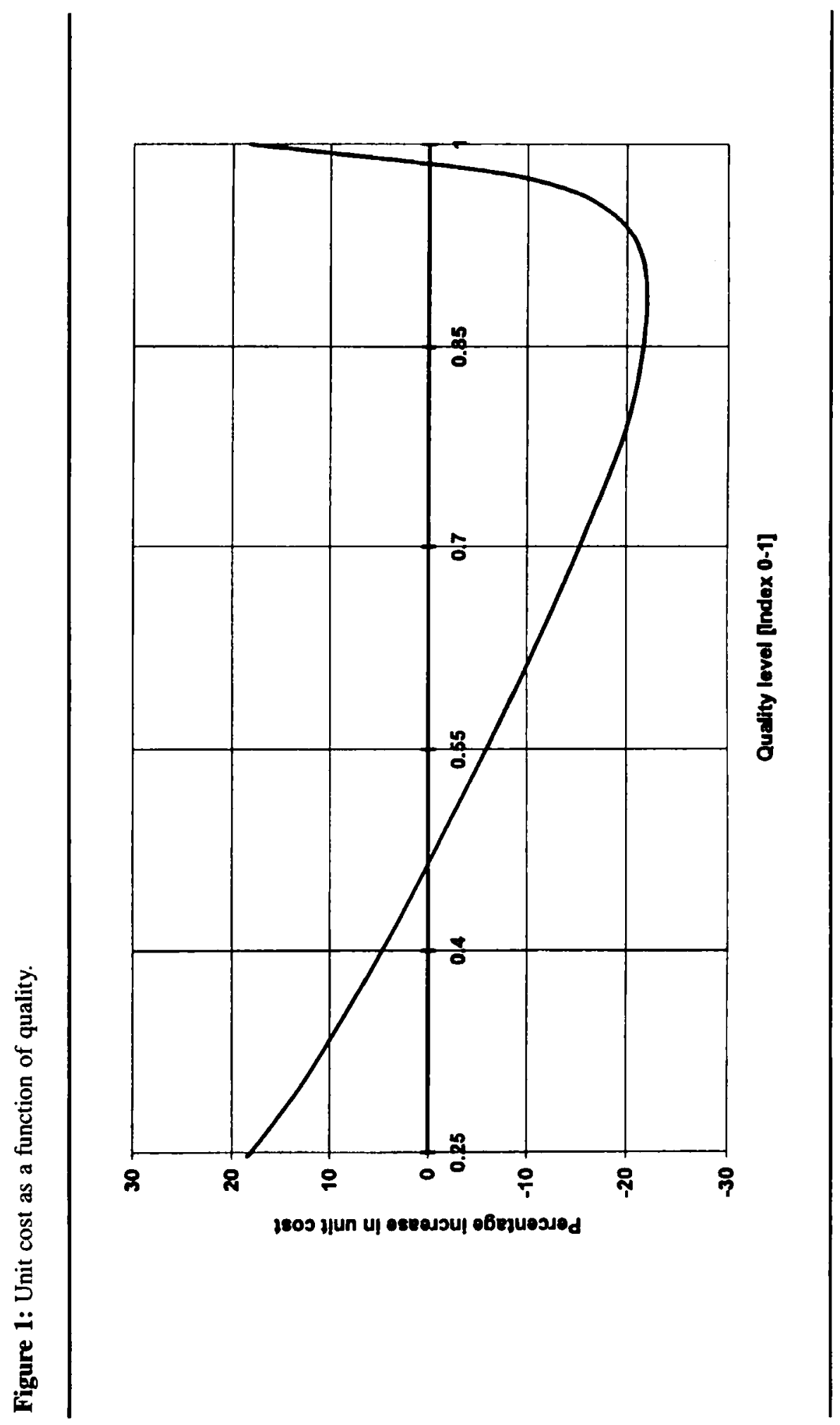


Table 1: Percentage increase in unit cost as a function of quality.

\begin{tabular}{cc}
$\begin{array}{c}\text { Quality } \\
\text { Level }(q)\end{array}$ & $\begin{array}{c}\text { Percentage Increase } \\
\text { in Unit Cost }\end{array}$ \\
\hline 0.25 & 18 \\
0.30 & 13 \\
0.40 & 5 \\
0.50 & -3 \\
0.60 & -9 \\
0.70 & -15 \\
0.80 & -20 \\
0.90 & -22 \\
0.95 & -18 \\
0.98 & -4 \\
0.99 & 5 \\
1 & 18 \\
\hline
\end{tabular}

This nonlinear, asymmetric specification is a plausible representation of the cost function, which captures the different perspectives in current literature on the behavior of cost [36]. In this research, the percentage changes shown in the quality-cost function are applied to a base cost of $\$ 2,000$.

\section{Solution Method}

In view of the complexity of the model, we chose not to apply a standard optimal control theory or calculus of variation approach to obtain a solution to the optimal control problem. Even though, using standard methods, the necessary conditions for the optimal price trajectories can be readily derived, there is no guarantee that a closed-form solution for the optimal price trajectories or even a meaningful interpretation of the necessary conditions for optimality can be obtained. Although it is possible to numerically "solve" the necessary conditions for the optimal (price) trajectories (see, e.g., [34]) we chose to derive such trajectories from the model, using a direct, numerical solution approach.

Our solution approach consisted of specifying a finite number of points in time at which the price functions were allowed to change. The problem became one of obtaining a finite number of values for the control functions at specific epochs, to maximize the objective function. This problem, in general, is a nonlinear optimization problem [18].

Even though we do not have a closed-form expression for the objective function, for each set of proposed controls we can numerically solve for the behavior of the system through time by solving the differential equations that constitute the model. Then the performance measure can be readily computed.

To obtain the vector of optimal prices that maximizes the objective function, a numerical optimization routine was linked to the dynamic model to search the space generated by all possible combinations of control values at the specified times. This solution method is described in [1]. 
We used the Generalized Reduced Gradient (GRG) method to solve the nonlinear optimization problem. GRG has been used successfully to solve optimal control problems of the type considered in this paper [1]. Besides, a current version of the algorithm, GRG2 [20], is embedded in the "Solver" component of the Microsoft EXCEL spreadsheet software [37].

The GRG algorithm is a nonlinear extension of the simplex method for linear programming. Succinctly, the GRG algorithm solves nonlinear constrained optimization problems by systematically searching the feasible region for the optimal solution. At each step, the GRG algorithm uses the binding constraints to solve for $n$ variables, (called basic variables), in terms of the remaining $(m-n)$ variables (called nonbasic variables), reducing the dimensionality of the problem. The algorithm then moves to a new solution point in the direction of the gradient for the reduced problem, which improves the value of the objective function. These steps are repeated at subsequent candidate solution points until an optimum solution is identified. For details of the GRG algorithm, the reader is referred to Lasdon, Waren, Jain, and Ratner [20].

In deriving the optimal trajectories for price using this technique, equations (1) to (6) that comprise the model were numerically solved. The differential equations (3) and (4) were numerically integrated using the Euler method [23] to yield the time paths of the state variables $X_{t}$ and $Y_{t}$. For the numerical integration, a time step of 0.1 years was used. This value was chosen to ensure the stability of the Euler method. Costs for different levels of quality were obtained by fitting a Lagrange interpolation polynomial [35] to the assumed quality-percentage change in cost, $\left(q_{i}, \Delta C_{i}\right)$, values in Table 1 . The expression for the interpolating polynomial is:

$$
\Delta C(q)=\sum_{i=1}^{i=N} \Delta C_{i} \prod_{\substack{j=1 \\ j \neq i}}^{j=N} \frac{\left(q-q_{j}\right)}{\left(q_{i}-q_{j}\right)},
$$

where $\Delta C(q)$ represents the increase in unit cost as a function of quality.

The numerical solution was carried out in an EXCEL worksheet. The values for price, one of the two control variables in the model, were specified for epochs 6 months apart; linear interpolation was used to join the semiannual prices into a continuous control function. The performance measure was the discounted profit at various terminal times, using a discount rate of $7 \%$.

The nonlinear optimization algorithm GRG2, iteratively varied the price vector to maximize total discounted profit. In essence, the Euler solution of the differential equations behaved as an implicit nonlinear function connecting a vector of prices (indexed by time) to total discounted profit at the terminal target time (a scalar). The nonlinear routine was used to maximize this implicit function.

The interaction between GRG2 and the dynamic model whose performance we sought to optimize is illustrated in Figure 2. As shown, linear interpolation was performed on the price vectors from GRG2, which contained values for price at specified epochs to create a price trajectory. Using the price trajectory thus derived, specified values for the parameters and the quality function, the NGM model was numerically solved using Euler integration and total discounted profit at terminal 


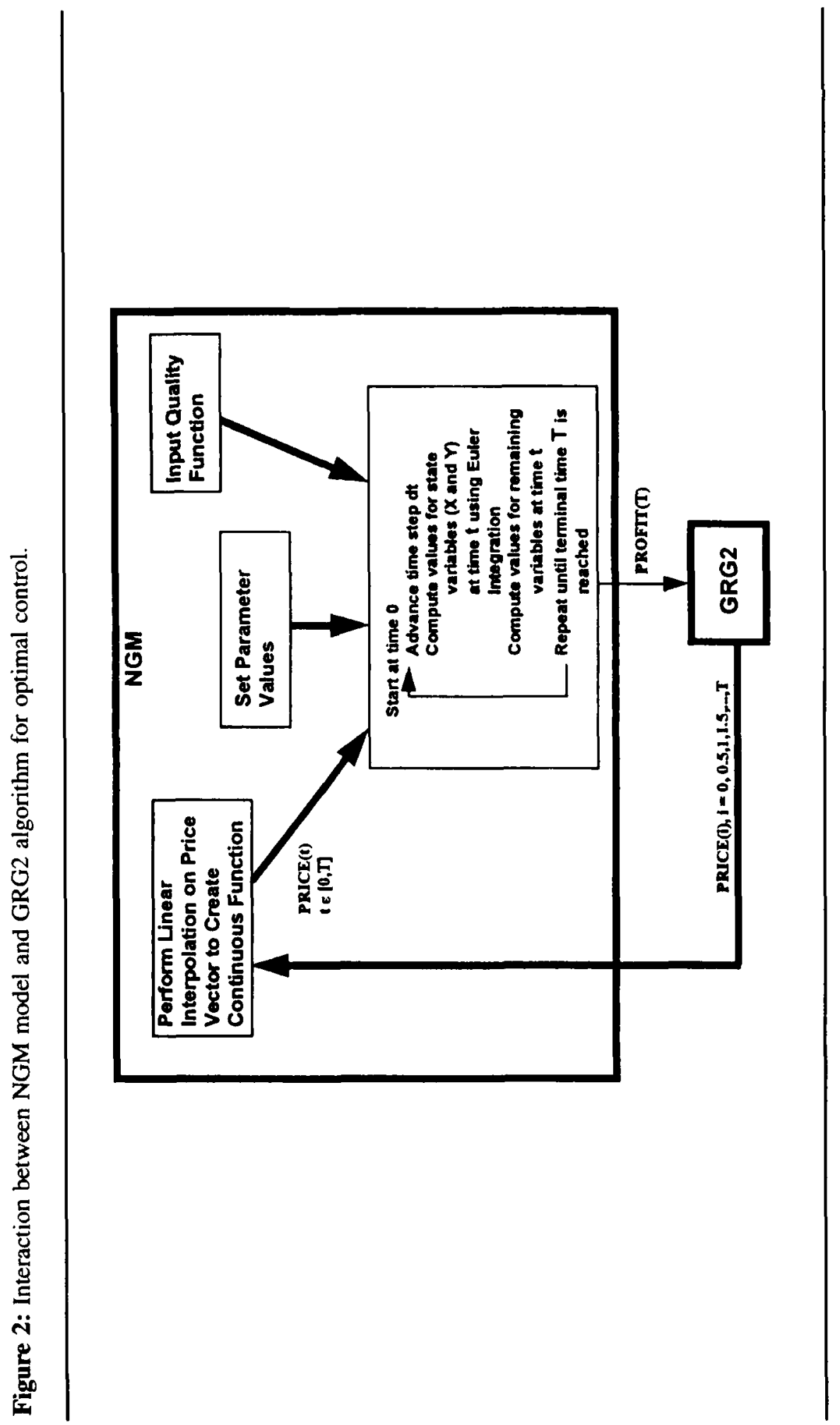


time $\Pi(T)$ was computed. Total profit was fed back to GRG2, which generated another vector of prices. The process was repeated until the GRG2 convergence criteria were met. In our computations, the operating and convergence parameters of the GRG2 algorithm were left at the default values set in the Microsoft Excel Solver implementation.

\section{SCENARIO ANALYSES}

Given a profit maximization objective, the research questions of interest were:

1. Is the optimal price trajectory influenced by the average life of a product? If yes, what is the nature of this relationship?

2. How does the optimal price trajectory behave in the presence of continuous quality improvements?

3. Does the optimal price trajectory depend on the persistence of quality perceptions? If yes, what is the nature of this relationship?

4. Does the qualitative nature of these relationships change when a short planning horizon versus a long planning horizon is considered?

The motivation for these research questions stems from the importance of the pricing decision to the competitiveness of the firm. We examine the case of a durable goods producer who is increasing product quality over time (quality disimprovements are not considered in our model) and must set prices to maximize profits. However, it is to be noted that quality is a control variable. Since our primary focus is on the optimal pricing decision, we do not seek optimal trajectories for quality under the various scenarios considered in deriving optimal solutions using the model. The specification of a linear trajectory for quality over time captures the spirit of continuous quality improvement without being unduly restrictive.

As a firm increases quality, it is not obvious what pricing strategy is optimal [29]. For example, price increases in view of quality improvements may be appropriate under certain conditions (such as pursuing niche markets with premium products). Prices can also be lowered, if the objective is to maximize value to the customer and to achieve rapid market penetration. Similarly, it is not obvious whether prices should be increased as the durability of a product is increased. It is also important to understand the relationship between the speed of diffusion of quality improvements and optimal prices. The optimal price trajectory and the resulting profits often determine the amount that can be spent on advertising and promotion. This relationship is somewhat complex in that advertising and promotion can be used to increase the persistence effect of quality improvements. The research questions were intended to shed some light on these issues and to generate insights about the behavior of optimal prices.

Several scenario analyses were done to address the research questions of interest by varying the parameters in the model and assessing their effect on the optimal price trajectories. The parameters that were varied in the scenario analyses were $D 1$ - the average life of the product, $D 2$-the persistence effect of quality improvements (i.e., the average length of time that the quality of a unit continues to affect sales by influencing customer perception of quality), and the demand elasticity of 
the product. The parameter for demand elasticity was set at 0.7 and 1.3 to represent price-inelastic demand and price-elastic demand, respectively. Although the model does not explicitly incorporate competition, the effect of competition on the ability of a firm to set prices is indirectly captured through the price elasticity of demand [30]. We acknowledge that price elasticity of demand could vary over the life of a product. However, we have chosen to use these parameter values in the sense of averages corresponding to price-inelastic and price-elastic demand cases. It is to be noted that the constant demand elasticity value of 1.3 was used to validate the NGM model. Also, to study the impact of a short-term versus a long-term orientation on optimal price trajectories, the length of the planning horizon was varied in the scenario analyses. All possible combinations of the following parameter levels were investigated:

Average life of product $(D 1): 3,5$, and 10 years,

Planning horizon $(T)$ :

$0.5 \times D 1,2 \times D 1$ years,

Quality persistence $(D 2)$ :

$0.25 \times D 1,0.5 \times D 1,0.75 \times D 1$ years, and

Demand elasticity $(e)$ :

0.7 (inelastic), 1.3 (elastic).

In total, 36 optimal control problems were solved to derive the optimal price trajectories. The parameter $\alpha$ and the initial values for the state variables $\left(X_{0}\right.$ and $\left.Y_{0}\right)$ were set at the values estimated in [28]. The parameter $\alpha$ was not altered in the scenario analyses ( $\alpha$ is a measure of the speed at which a product diffuses through a population). There are no external sources of data that can provide values for this parameter, so it has to be estimated within the model from historical data. The variation of $\alpha$ would not provide any managerial insight because there are no measures that link this parameter with interpretable market conditions. We tested the sensitivity of the optimal price trajectories to variations in $\alpha$. The optimal price trajectories were essentially unchanged for a 50\% change in the values of $\alpha$. As indicated before, the cost function was modeled as a nonlinear function of the current quality level of the products. Other factors that can affect the cost function, such as economies or diseconomies of scale or learning effects, were not included in the formulation to keep the analysis sharply focused on issues of interest in this research.

In our research, we treat the composite measure of quality as an index between 0 and 1,1 being the maximum attainable level of quality. This is consistent with the formulation in [28]. In all the scenarios, quality increases linearly from a "low" level $(0.25)$ at time 0 , to a maximum level of 1 at terminal time $T$. Since $T$ is varied in the numerical computations, implicitly, the rapidity of quality improvements is also varied in the various scenarios considered (that is, scenarios with lower values of $T$ correspond to more rapid quality improvements than those with higher values of $T$ ). Table 2 shows the parameter values used in solving the optimization problems.

\section{DISCUSSION OF RESULTS}

The results of the scenario analyses (optimal trajectories) are shown in Figures 3 and 4.

\section{Price Elastic Demand; Average Life of Product, $D 1=10$}

Comparing scenarios $3 \mathrm{f}-\mathrm{A}$ and $3 \mathrm{e}-\mathrm{A}$ where $D 2 / D 1=0.75$, it can be seen that for the case $T=20$ (corresponding to a longer time horizon), price increases initially and 
Table 2: Numerical values used in optimization runs.

\begin{tabular}{cl}
\hline Parameters & \multicolumn{1}{c}{ Values } \\
$\alpha$ & 0.00124 [units-years] \\
$e$ & $0.7,1.3$ \\
$D 1$ & $3,5,10$ years \\
$D 2$ & $0.25 D 1,0.5 D 1,0.75 D 1$ \\
$T$ & $0.5 D 1,2 D 1$ \\
$M_{0}$ & 2.4 million units \\
$P_{0}$ & $\$ 2,000$ \\
$r$ & 0.07 \\
Control & \\
Variables & Trajectories \\
$P_{t}$ & Optimal trajectories \\
$q_{t}$ & Prespecified trajectory (Linearly increasing \\
& from 0.25 at $t=0$ to 1 at $t=T$ ) \\
State Variables & Initial Values \\
$Y_{0}$ & 329.64 units/year \\
$X_{0}$ & 248.33 units/year \\
\hline
\end{tabular}

then decreases by the terminal time to 2,200 , which is lower than the initial price of 3,300. For the case $T=5$ (corresponding to a shorter planning horizon), price declines from approximately 3,450 to 2,100 by the terminal time. A comparison of scenarios $3 \mathrm{f}-\mathrm{B}$ and $3 \mathrm{e}-\mathrm{B}$, where $D 2 / D 1=0.50$, shows that qualitative behavior of the optimal price trajectories for these two cases is similar to that of the previous two cases for the planning horizons. However, even though initial and terminal optimal prices are approximately the same as in scenarios $3 \mathrm{f}-\mathrm{A}$ and $3 \mathrm{e}-\mathrm{A}$, the transition prices are lower for these two cases. Comparison of scenarios $3 \mathrm{f}-\mathrm{C}$ and $3 \mathrm{e}-\mathrm{C}$, where $D 2 / D 1=0.25$, shows that prices decline throughout the planning horizon, and the transition prices are lower than those in the previous scenarios. The following observations can be made about the behavior of optimal price trajectories:

- Regardless of the magnitude of the ratio $D 2 / D 1$, optimal prices generally decline over the planning horizon (i.e., the optimal terminal prices are consistently lower than the optimal initial prices).

- Optimal pricing decisions depend on the planning horizon. A longer term orientation leads to optimal price trajectories that call for an increase in price followed by decreases. As time elapses and quality improvements diffuse through the market, price is decreased to accelerate sales and to achieve market penetration through "value pricing." This price behavior conforms to observations made by researchers in marketing and in the area of manufacturing strategy. Hayes and Wheelwright [14] have discussed the switch from "quality sensitivity" to "price sensitivity" as a product moves through its life cycle. Hill [15] refers to the shift from quality as an order winner to an order qualifier over the product life cycle. 
Figure 3: Optimal controls derived under elastic demand.

a. $D 1=3 \quad T=1.5$

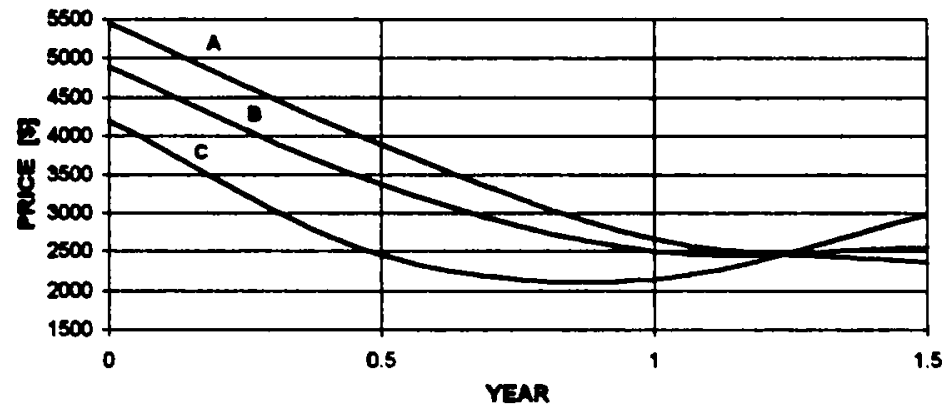

\section{b. $D 1=3 \quad T=6$}

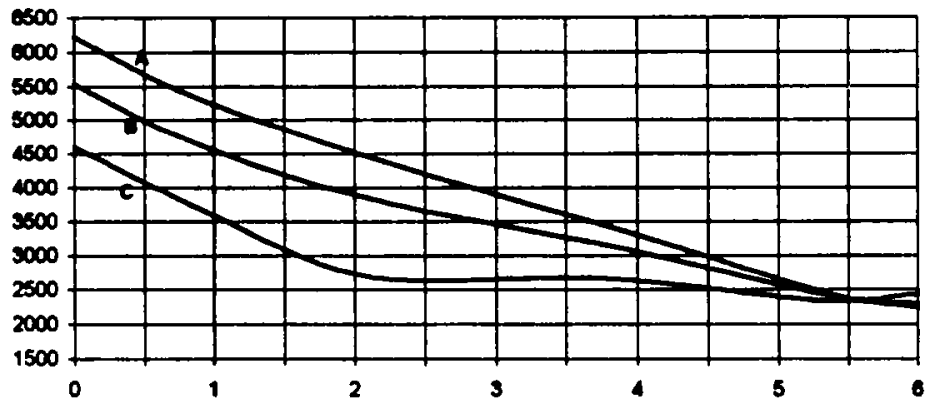

c. $D 1=5 \quad T=2.5$

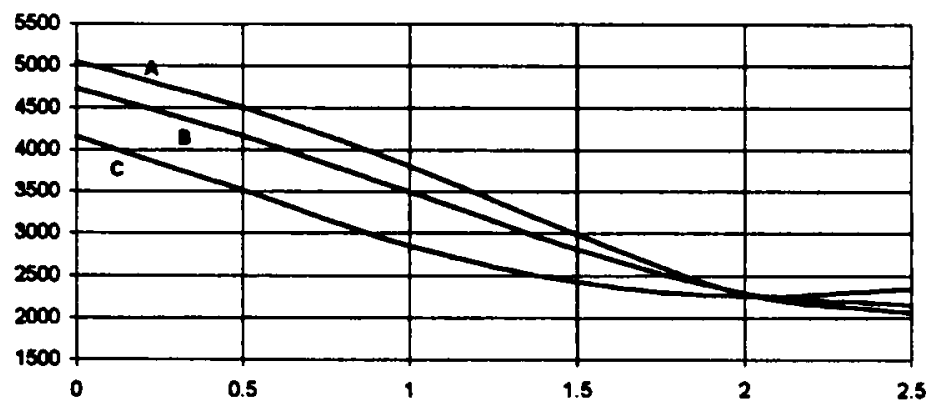


Figure 3: (continued).

\section{d. $D=5 \quad T=10$}

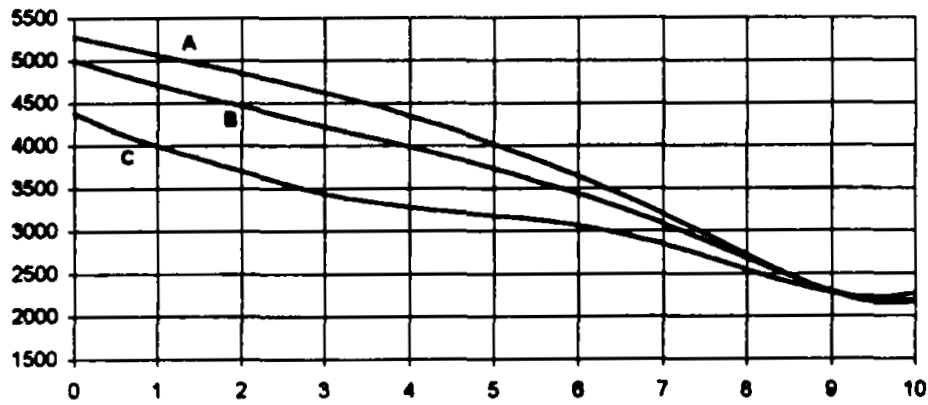

\section{e. $D 1=10 \quad T=5$}

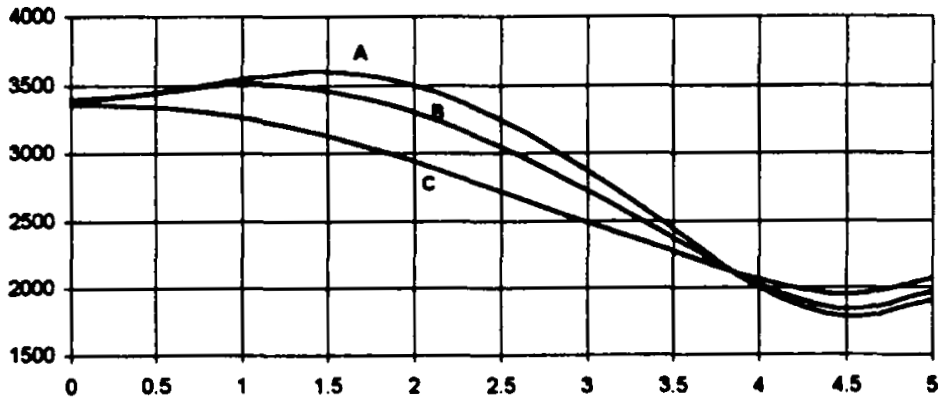

\section{f. $D 1=10 \quad T=20$}

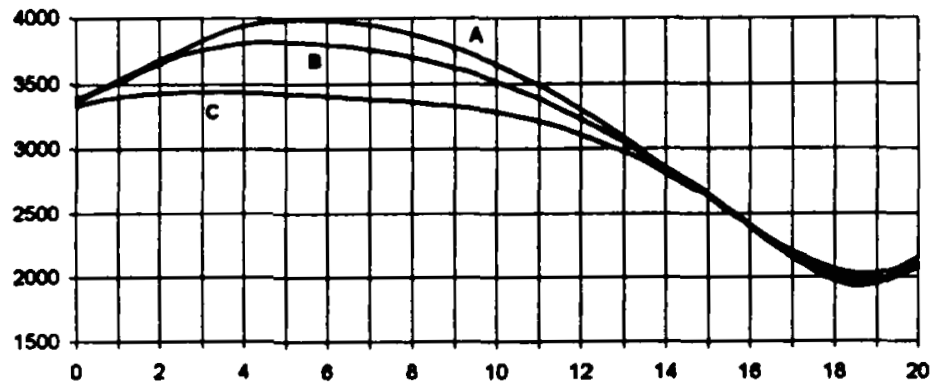

$D 1=$ Average life of the product; $D 2=$ Persistence of quality perceptions; elasticity $=1.3$

A: $D 2=0.75 D 1 \quad$ B: $D 2=0.50 D 1 \quad$ C: $D 2=0.25 D 1$ 
Figure 4: Optimal controls derived under inelastic demand.

a. $D 1=3 \quad T=1.5$

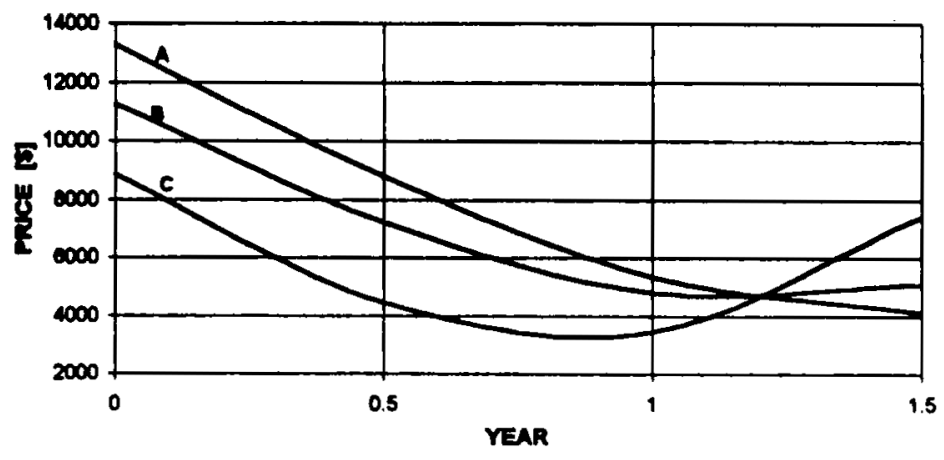

\section{b. $D 1=3 \quad T=6$}

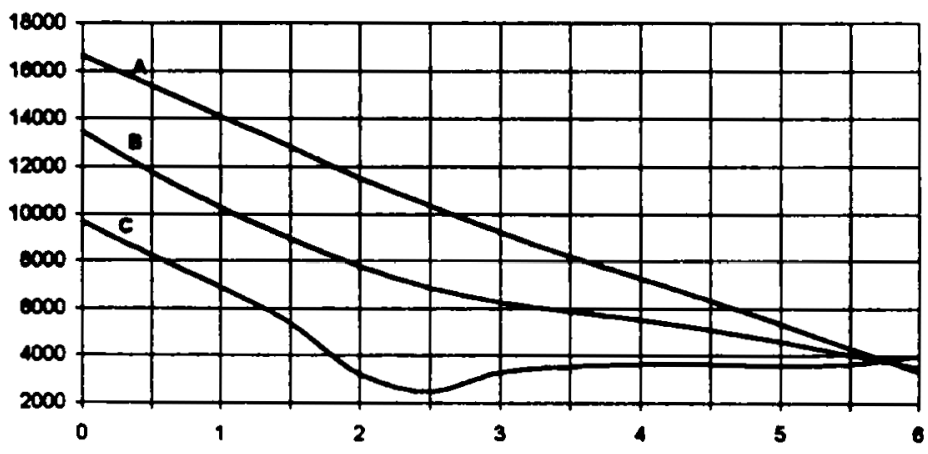

\section{c. $\mathrm{D1}=5 \mathrm{~T}=2.5$}

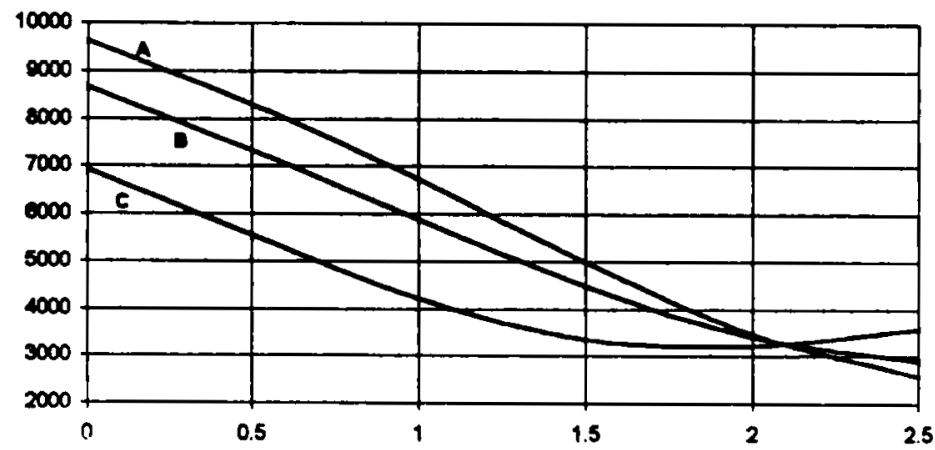


Figure 4: (continued).

d. $D 1=5 \quad T=10$

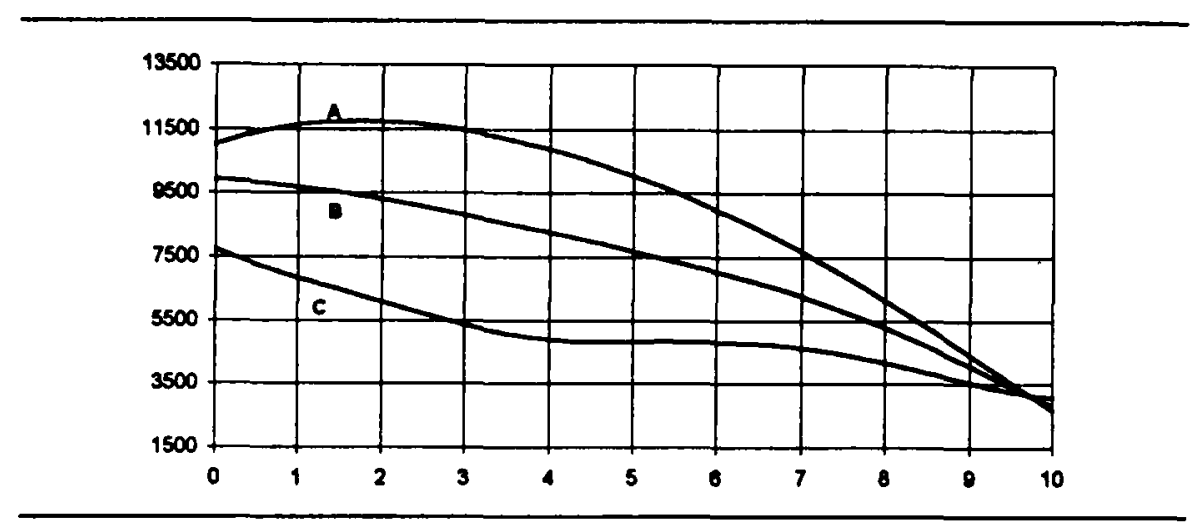

e. $D 1=10 \quad T=5$

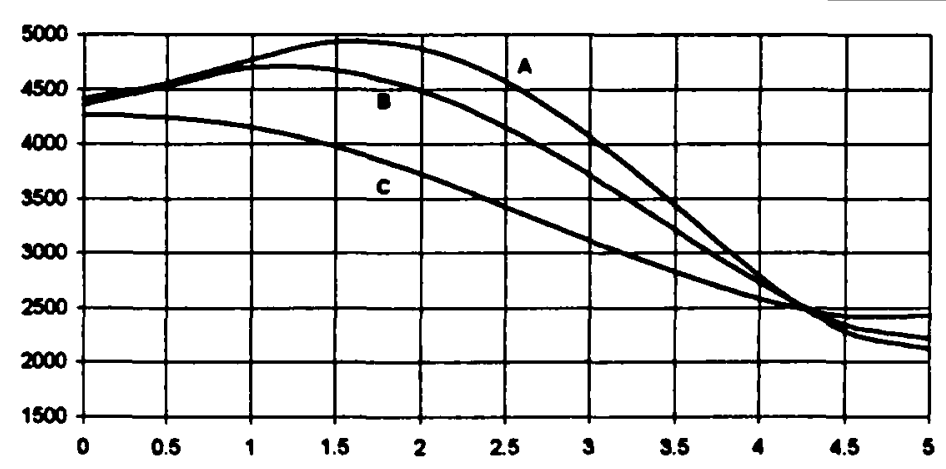

\section{f. $D 1=10 \quad T=20$}

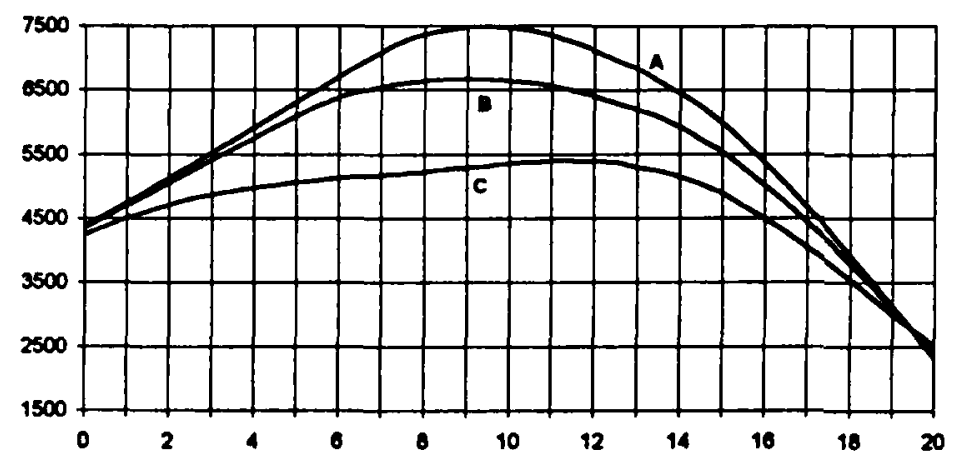

$D 1=$ Average life of the product; $D 2=$ Persistence of quality perceptions; elasticity $=0.7$
A: $D 2=0.75 D 1$
B: $D 2=0.50 D 1$
C: $D 2=0.25 D 1$ 
- Optimal price trajectory depends on the $D 2 / D 1$ ratio as well as the length of the planning horizon. Higher values for $D 2$, which correspond to longer duration over which quality diffusion effects persist, are associated with higher initial prices and higher transition prices during the expansionary phase of the product life cycle. This optimal price behavior is observed consistently in scenarios $3 \mathrm{f}-(\mathrm{A}, \mathrm{B}, \mathrm{C})$ and $\mathrm{Be}-(\mathrm{A}, \mathrm{B}, \mathrm{C})$.

- When we examine shorter term horizon results in Figure $3 \mathrm{e}$, rates of price increases and decreases are higher compared to the results in Figure $3 \mathrm{f}$. Initial and terminal prices are about the same in Figures $3 \mathrm{e}$ and $3 \mathrm{f}$.

\section{Price-Elastic Demand; Average Life of Product, $D 1=5$}

Comparison of scenarios $3 \mathrm{~d}-\mathrm{A}, 3 \mathrm{c}-\mathrm{A}, 3 \mathrm{~d}-\mathrm{B}$, and $3 \mathrm{c}-\mathrm{B}$, corresponding to $D 2 / D 1$ ratios of 0.75 and 0.50 , and $T$ values of 10 and 2.5 shows that optimal price trajectory declines throughout the planning horizon. The initial optimal price is dependent on the $D 2 / D 1$ ratio. The larger the value of the $D 2 / D 1$ ratio, the higher the initial optimum prices (compare, for example, scenarios $3 \mathrm{~d}-\mathrm{A}$ and $3 \mathrm{~d}-\mathrm{B}$ ). Comparison of scenarios $3 \mathrm{~d}-\mathrm{C}$ and $3 \mathrm{c}-\mathrm{C}$ corresponding to a $D 2 / D 1$ ratio of 0.25 shows that the optimal price trajectory declines from an optimum price initially followed by a slight increase in the latter stages in run $3 \mathrm{c}-\mathrm{C}$. The price increase observed in run $3 \mathrm{c}-\mathrm{C}$ towards the end of the planning horizon is not seen in run $3 \mathrm{~d}-\mathrm{C}$, corresponding to the longer planning horizon ( $T=10$ years). The following observations can be made in reviewing the behavior of the optimal price trajectories:

- Optimal price behavior for $D 2 / D 1=0.75$ and 0.50 is different from the behavior corresponding to $D 1=10$ for the same $D 2 / D 1$ ratios. Therefore, it can be inferred that the average life of the product (an aspect of quality that is influenced by product design, manufacturing quality and materials used) does affect the trajectory of optimal prices. The observed differences in optimal trajectories also reflect the influence that average life of the product has on the proportion of the market that is saturated at any given time.

- Although the optimal trajectories are similar for $D 2 / D 1$ values of 0.75 and 0.50 , the behavior is different for the case when $D 2 / D 1=0.25$. This further underscores the linkage between optimal prices and product quality.

- Optimal initial prices and price trajectories are related to the value of D2. Higher values of $D 2$ are consistently associated with higher initial prices.

\section{Price-Elastic Demand; Average Life of Product, $D 1=3$}

Scenarios $3 a-(A, B, C)$ and $3 b-(A, B, C)$ correspond to this combination of parameter settings. Scenarios $3 \mathrm{~b}-\mathrm{A}, 3 \mathrm{a}-\mathrm{A}, 3 \mathrm{~b}-\mathrm{B}$, and $3 \mathrm{a}-\mathrm{B}$, corresponding to $D 2 / D 1$ ratios 0.75 and 0.50 indicate that optimal prices decline from an initial price throughout the time horizon. However, the optimal price behavior is markedly different when $D 2 / D 1=0.25$ (compare $3 \mathrm{a}-\mathrm{C}$ and $3 \mathrm{~b}-\mathrm{C}$ ). For the shorter planning horizon, optimal price trajectory initially declines, reverses course and increases for the remainder of the planning horizon. For the longer planning horizon $(3 b-C)$, price declines initially and exhibits slight fluctuating behavior as the terminal time is approached. The 
dependence of optimal prices on the ratio $D 2 / D 1$ and the value of $D 2$ can be seen in these scenarios also.

\section{Price-Inelastic Demand; Average Life of Product, $D 1=10$}

Scenarios $4 \mathrm{f}-(\mathrm{A}, \mathrm{B}, \mathrm{C})$ and $4 \mathrm{e}-(\mathrm{A}, \mathrm{B}, \mathrm{C})$ show the optimal price trajectories for a relatively inelastic product for $D 2 / D 1$ ratio values of $0.75,0.50$ and 0.25 . The optimal price trajectories in scenarios $4 \mathrm{f}-\mathrm{A}, 4 \mathrm{e}-\mathrm{A}, 4 \mathrm{f}-\mathrm{B}$, and $4 \mathrm{e}-\mathrm{B}$ differ from those corresponding to an elastic product. Optimal price trajectory increases from an initial price, attains a maximum and then decreases to an optimal terminal price that is less than the initial optimum price. The magnitude of the price increases relative to the initial prices are larger in these scenarios compared to similar scenarios for the higher elasticity case. In scenario $4 \mathrm{e}-\mathrm{C}$, corresponding to $D 2 / D 1=0.25$ for the shorter planning horizon $(T=5)$, price decreases from the initial optimal price over the planning horizon. However, in scenario $4 \mathrm{f}-\mathrm{C}$, which corresponds to the same $D 2 / D 1$ ratio for the longer time horizon $(T=20)$, optimal price increases for more than half of the planning horizon, which is very different from the corresponding elastic-demand case. The following observations can be made about the relationship of optimal price trajectory to the parameters in the model:

- Optimal price policies are related to the demand elasticity of the product, as shown by comparison of scenarios $3 \mathrm{f}-\mathrm{A}$ and $4 \mathrm{f}-\mathrm{A}$. Relative inelasticity of demand affords an opportunity to charge higher prices immediately following quality improvements, thus allowing faster recovery of investments made in quality improvements.

- Price increase is sharper when the $D 2 / D 1$ ratio is larger. For example, when $D 2 / D 1=0.75$, price increases from 4400 to 7500 in 9.5 years (see run $4 \mathrm{f}-\mathrm{A}$ ) as compared to an increase from 4400 to 6700 in 9 years when $D 2 / D 1=0.50$ (see run $4 \mathrm{f}-\mathrm{B}$ ).

- As observed previously for the case of high elasticity, there is interaction effect between $D 1, D 2$, and the planning horizon. Comparing scenarios $4 \mathrm{f}-\mathrm{A}, 4 \mathrm{e}-\mathrm{A}, 4 \mathrm{f}-\mathrm{B}$, and $4 \mathrm{e}-\mathrm{B}$, shows that higher values for $\mathrm{D} 2$ (corresponding to scenarios in which quality diffusion effect persists longer) are accompanied by generally higher prices regardless of the length of the planning horizon. These results underscore, as in previous scenarios, the relationship between quality and optimal price trajectories.

\section{Price-Inelastic Demand; Average Life of Product, $D 1=5$}

Scenarios $4 \mathrm{~d}-(\mathrm{A}, \mathrm{B}, \mathrm{C})$ and $4 \mathrm{c}-(\mathrm{A}, \mathrm{B}, \mathrm{C})$ corresponding to these parameter settings show a variety of optimal price behavior. When $D 2 / D 1=0.75$ and the planning horizon is long (run $4 \mathrm{~d}-\mathrm{A}$ ), price behavior is concave. Price increases from 10800 to 11800 and decreases for the remainder of the planning horizon. This differs from the optimal price trajectory under similar conditions for $D 1=10$, in that the initial price is considerably higher, price increases relative to the initial price are lower and price increases are not sustained as long as in the $D 1=10$ case, suggesting a strong influence from the average life of the product. Scenarios $4 \mathrm{c}-\mathrm{A}$ and $4 \mathrm{c}-\mathrm{B}$ for 
a shorter time horizon, show that optimal price trajectory declines from an initial optimal price. Scenarios $4 \mathrm{~d}-\mathrm{C}$ and $4 \mathrm{c}-\mathrm{C}$ corresponding to $D 2 / D 1=0.25$ show that optimal prices should decrease at first and possibly increase during the planning horizon. In $4 \mathrm{~d}-\mathrm{C}$, price declines after year 7 . The length of time over which prices decline and the magnitude of the decline are related to the length of the planning horizon. The following observations can be made about the behavior of optimal price trajectories:

- Optimal prices depend on $D 1, D 2$, and the length of the planning horizon. For higher values of $D 2 / D 1$, higher prices are suggested.

- The duration over which prices decline (or increase) and the magnitude of the decrease (increase) are influenced by the planning horizon as well as $D 2$, the length of time over which quality diffusion persists.

\section{Price-Inelastic Demand; Low Average Life, $D 1=3$}

Scenarios $4 b-(A, B, C)$ and $4 a-(A, B, C)$ correspond to these parameter settings. Scenarios corresponding to $D 2 / D 1$ ratios of 0.75 and 0.50 indicate that the optimal prices generally decline over the planning horizon. Starting optimal prices are dependent on the value of $D 2$ (16500 versus 13500 for scenarios $4 \mathrm{~b}-\mathrm{A}$ and $4 \mathrm{~b}-\mathrm{B}$, corresponding to $D 2$ values of 2.25 and 1.5 , respectively). As discussed in previous sections, when $D 2 / D 1=0.25$, optimal price behavior is markedly different from that observed in scenarios $4 \mathrm{~b}-\mathrm{A}, 4 \mathrm{a}-\mathrm{A}, 4 \mathrm{~b}-\mathrm{B}$, and $4 \mathrm{a}-\mathrm{B}$. When $D 2 / D 1=0.25$, price initially decreases and then increases for the remainder of the planning horizon. Table 3 shows the optimal profits attained under the different scenarios.

\section{DISCUSSION OF MANAGERIAL SIGNIFICANCE}

The previous sections have presented the results of solving the optimal control model for a number of scenarios by varying the parameters in the model. The results of analyzing the individual scenarios can be synthesized into the following conclusions:

1. Optimal price trajectories are dependent on demand elasticity of the product, which coincided with our prior expectation. While it can be reasoned that when demand elasticity is high, price increases will be detrimental to sales and profits (and that there will be greater price flexibility when demand elasticity is low), the exact nature of the optimal price trajectories cannot be readily discerned. The numerical solutions not only show the behavior of the different optimal trajectories for the two cases (high versus low elasticity) but also the timing and magnitude of price increases and decreases. For both cases of demand elasticity, prices decline as well as increase depending on the values of the other parameters. Demand elasticity interacts with the average life of the product and the persistence effect of quality diffusion.

2. The ratio of average life of product $(D 1)$ to the persistence of quality diffusion parameter $(D 2)$ seems to play an important role in the behavior of optimal price trajectories. Regardless of the elasticity of demand, there is an interaction effect (on optimal prices) between the length of planning horizon and the ratio of $D 2$ to $D 1$. 
Table 3: Optimal discounted profits.

\begin{tabular}{lccc}
\hline Scenario & $\begin{array}{c}\text { Optimal Profit } \\
\text { (in billions of dollars) }\end{array}$ & Scenario & $\begin{array}{c}\text { Optimal Profit } \\
\text { (in billions of dollars) }\end{array}$ \\
\hline 3a-A & 3.47 & $4 \mathrm{a}-\mathrm{A}$ & 6.37 \\
3a-B & 2.55 & $4 \mathrm{a}-\mathrm{B}$ & 4.40 \\
3a-C & 1.23 & $4 \mathrm{a}-\mathrm{C}$ & 1.83 \\
3b-A & 7.86 & $4 \mathrm{~b}-\mathrm{A}$ & 16.04 \\
3b-B & 6.32 & $4 \mathrm{~b}-\mathrm{B}$ & 11.55 \\
3b-C & 3.66 & $4 \mathrm{~b}-\mathrm{C}$ & 5.21 \\
3c-A & 4.24 & $4 \mathrm{c}-\mathrm{A}$ & 7.06 \\
3c-B & 3.54 & $4 \mathrm{c}-\mathrm{B}$ & 5.65 \\
3c-C & 2.27 & $4 \mathrm{c}-\mathrm{C}$ & 3.19 \\
3d-A & 7.47 & $4 \mathrm{~d}-\mathrm{A}$ & 14.96 \\
3d-B & 6.58 & $4 \mathrm{~d}-\mathrm{B}$ & 12.36 \\
3d-C & 4.65 & $4 \mathrm{~d}-\mathrm{C}$ & 7.45 \\
3e-A & 2.87 & $4 \mathrm{e}-\mathrm{A}$ & 3.53 \\
3e-B & 2.60 & $4 \mathrm{e}-\mathrm{B}$ & 3.16 \\
3e-C & 2.05 & $4 \mathrm{e}-\mathrm{C}$ & 2.34 \\
3f-A & 4.18 & $4 \mathrm{f}-\mathrm{A}$ & 7.20 \\
3f-B & 3.93 & $4 \mathrm{f}-\mathrm{B}$ & 6.60 \\
3f-C & 3.30 & $4 \mathrm{f}-\mathrm{C}$ & 5.14 \\
\hline
\end{tabular}

Note: Comparisons of optimal profits in the table should be made in the light of different product durabilities $(D 1)$, quality persistence $(D 2)$, and discounting effects.

To interpret this result managerially, $D 1$ and $D 2$ need to be viewed more conceptually, rather than as delay parameters in the model. $D 1$, which corresponds to the average life of the product, can be construed to represent the effect of product design, quality of materials used and the effectiveness of manufacturing processes. Although these aspects were not explicitly considered in the model, the level of aggregation represented by the parameter $D 1$ reflects such an interpretation. $D 2$, which captures the persistence effect of quality improvements is (can be) influenced by a firm's marketing, sales, and promotion efforts. That is, through its marketing efforts (aimed at creating brand loyalty and image), a firm can influence the "quality life" of a product. Intensive efforts in this regard extend the quality life of a product (i.e., increase $D 2$ and prolong positive perception of the product in the minds of customers).

When interpreted in this manner, this result suggests that when engineered product quality is high (high $D 1$ ) and the product is not heavily promoted (low $D 2$ ) so that $D 2 / D 1$ is low, the optimal price strategy is to price the product aggressively and let the diffusion effect of quality take hold before raising prices in the wake of quality improvements. This insight regarding the interaction of $D 1, D 2$ and optimal pricing is interesting from a theoretical as well as practical perspective.

3. The average life of a product affects the optimal price trajectories in important ways. In general, higher values for $D 1$ support higher initial optimal prices, thus suggesting a strong dependence between "quality" and pricing decisions. 
4. The persistence effect of quality has an influence on optimal pricing trajectories. The higher the value of $D 2$ in the scenarios, the higher the prices (initial prices, price increases, etc.). The value of this parameter can be influenced by advertising and promotion. The model characterizes the optimal pricing strategies to follow when such a tactic is pursued.

5. Conclusions 3 and 4 above indicate that there is a relationship between pricing decision and product quality. In the marketing literature (see, e.g., [13]), correlational analysis of price-quality data has been used to assert that the relationship between price and quality may be weak. The optimal trajectories for price, derived in this paper, when viewed in conjunction with the quality trajectory suggest that there is a relationship between price and quality. One possible explanation for this difference in results is that empirical data analyses (using cross-sectional data) have attempted to correlate quality with actual prices, not necessarily optimal prices. The results based on our model affirm the conclusions reached by Rao and Monroe [32] and Dodds, Monroe, and Grewal [9]. A dynamic model of the type analyzed in this paper is better at capturing the intricacies of the dynamic, nonlinear relationships between quality and price, and therefore is useful for generating insights.

6. The results also suggest that important interrelationships exist between pricing, positioning and promotion decisions, and manufacturing quality. Better understanding of this interrelationship will enable a firm to adopt appropriate pricing strategies to maximize its profit in the short or the long term.

\section{SUMMARY}

This paper investigated the optimal pricing decision in the presence of continuous quality improvements for a profit-maximizing firm. A dynamic (optimal control) model incorporating demand elasticity, life of a product, and diffusion effect of quality improvements was solved numerically using the generalized gradient procedure to derive optimal price trajectories. The solutions show that important linkages exist among optimal prices, average life of the product, and the persistence effect of quality perception. The results affirm some ideas from existing literature and suggest that there is a relationship between quality and price. The results also suggest that a more careful consideration of quality aspects in pricing and promotion decisions is warranted. For example, it is possible to have carryover effects of quality on a product line. The model presented in this paper does this by explicitly incorporating the parameters $D 1$ and $D 2$ on optimal pricing. The case $D 2>D 1$ would correspond to the situation where the quality perception exceeds the average life of the product.

The model discussed in this paper does not explicitly address the implications of rapidity of quality improvements on optimal price trajectories, which is a limitation. This aspect of the model merits further investigation. Also, investigation of the effect of possible changes in the demand elasticity over the life of a product merits further consideration. [Received: February 27, 1995. Accepted: December 14, 1995.] 


\section{REFERENCES}

[1] Abadie, J. Applications of the GRG algorithm to optimal control problems. In J. Abadie (Ed.), Nonlinear and integer programming. Amsterdam: North-Holland, 1972, 37-47.

[2] Banker, R.D., \& Khosla, I.S. Quality and competition. Working paper, Department of Operations and Management Science, Carlson School of Management, University of Minnesota, Minneapolis, Minnesota, 1992.

[3] Bass, F.M. A new product growth model for consumer durables. Management Science, 1969, 15, 215-227.

[4] Bagwell, K., \& Riordon, M.H. High and declining prices signal quality. The American Economic Review, 1991, 81(1), 224-239.

[5] Besanko, D., \& Winston, W.L. Optimal pricing of a product with periodic enhancements. European Journal of Operational Research, 1991, 55(2), 268278.

[6] Buzzell, R.D., \& Gale, B.T. The PIMS principles-Linking strategy to performance. New York: The Free Press, 1987.

[7] Cook, T. Pricing for maximum profit. Telephone engineer \& management, 1992, 96(10), 50-53.

[8] Dockner, E., \& Jorgensen, S. Optimal advertising policies for diffusion models of new product innovation in monopolistic situations. Management Science, $1988,34,119-130$.

[9] Dodds, W.B., Monroe, K.B., \& Grewal, D. Effects of price, brand, and store information on buyer's product evaluations. Journal of Marketing Research, 1991, 28, 307-319.

[10] Dolan, R.J., \& Jeuland, A.P. Experience curves and dynamic demand models: Implications for optimal pricing strategies. Journal of Marketing, 1981, 45, 52-73.

[11] Forrester, J.W. Principles of systems. Cambridge, MA: Wright-Allen Press, 1968.

[12] Garvin, D.A. Managing quality. New York: The Free Press, 1988.

[13] Gerstner, E. Do higher prices signal higher quality? Journal of Marketing Research, 1985, 22, 209-215.

[14] Hayes, R., \& Wheelwright, S. Restoring our competitive edge: Competing through manufacturing. New York: John Wiley, 1984.

[15] Hill, T. Manufacturing strategy: Text and cases. Boston, MA: Irwin, 1989.

[16] Kalish, S. Monopolist pricing with dynamic demand and production cost. Marketing Science, 1983, 2, 135-160.

[17] Kalish, S. A new product adoption model with price, advertising, and uncertainty. Management Science, 1985, 31, 1569-1585.

[18] Kirk, D.E. Optimal control theory: An introduction. Englewood Cliffs, NJ: Prentice-Hall, 1970.

[19] Kohli, R., \& Mahajan, V. A reservation-price model for optimal pricing of multiattribute products in conjoint analysis. Journal of Marketing Research, 1991, 28(3), 347-354. 
[20] Lasdon, L.S., Waren, A.D., Jain, A., \& Ratner, M. Design and testing of a generalized reduced gradient code for nonlinear programming. ACM Transactions on Mathematical Software, 1978, 4(1), 34-50.

[21] Lee, H.L., \& Tapiero, C.S. Quality control and the sales process. Naval Research Logistics Quarterly, 1986, 33, 569-587.

[22] Mahajan, V., Muller, E., \& Bass, F.M. New product diffusion models in marketing: A review and directions for research. Journal of Marketing, 1990, 54, 1-26.

[23] Manetsch, T.J., \& Park, G.L. Systems analysis and simulation with applications to economic and social systems. East Lansing, MI: Department of Electrical Engineering and System Science, Michigan State University, 1982.

[24] McClure, J.E., \& Spector, L.C. Joint product signals of quality. Atlantic Economic Journal, 1991, 19, 38-41.

[25] Mesak, H.I. Impact of anticipated competitive entry and cost experience on optimal strategic pricing of technological innovations. Computers and Operations Research, 1990, 17(1), 27-37.

[26] Monroe, K.B., \& Dodds, W.B. A research program for establishing the validity of the price-quality relationship. Journal of the Academy of Marketing Science, $1988,16,151-168$.

[27] Narasimhan, R., \& Ghosh, S. A dynamic model of manufacturing quality's effect on optimal advertising and pricing policies. European Journal of Operational Research, 1994, 72, 485-502.

[28] Narasimhan, R., Ghosh, S., \& Mendez, D. A dynamic model of product quality and pricing decisions on sales response. Decision Sciences, 1993, 24(5), 893-908.

[29] Narasimhan, R., \& Mendez, D. An investigation of the effect of product durability on monopolistic pricing. Proceedings of the 1992 Midwest Decision Sciences Institute Conference, 1992.

[30] Pindyck, R., \& Rubinfeld, D. Microeconomics. Englewood Cliffs, NJ: Prentice Hall, 1995.

[31] Plunkett, J.J., \& Dale, B.G. Quality costs: A critique of some economic cost of quality models. International Journal of Production Research, 1988, 26(11), 1713-1726.

[32] Rao, A.R., \& Monroe, K.B. The effect of price, brand name, and store name on buyer's perceptions of product quality: An integrated review. Journal of Marketing Research, 1989, 26, 351-357.

[33] Robinson, B., \& Lakhani, C. Dynamic price models for new product planning. Management Science, 1975, 21, 1113-1122.

[34] Roth, A.V., Gaimon C., \& Krajewski, L. Optimal acquisition of FMS technology subject to technological progress. Decision Sciences, 1991, 22, 308-334.

[35] Scheid, F. Numerical analysis. New York: McGraw-Hill, 1968.

[36] Shank, J. K., \& Govindarajan, V. Strategic cost management. New York: Free Press, 1993.

[37] Smith, S., \& Lasdon, L. Solving large sparse nonlinear programs using GRG. ORSA Journal on Computing, 1991, 4(1), 1-15. 
[38] Tapiero, C.S., Ritchken, P.H., \& Reisman, A. Reliability, pricing and quality control. European Journal of Operational Research, 1987, 31, 37-45.

[39] Thompson, G.L., \& Teng, J.T. Optimal pricing and advertising policies for new product oligopoly models. Marketing Science, 1984, 3, 148-168.

Ram Narasimhan is a professor of management in the Eli Broad Graduate School of Management at Michigan State University. He holds a B.S. in mechanical engineering, an M.S. in industrial engineering and a $\mathrm{Ph} . \mathrm{D}$. in management science from the University of Minnesota. He has published in Management Science, Decision Sciences, European Journal of Operations Research, International Journal of Production Research, and Interfaces, among others. He serves as an associate editor of the Journal of Operations Management. He is a member of the Decision Sciences Institute, Academy of Management, APICS, and INFORMS.

David Mendez is a Paul Comely Postdoctoral Fellow in the School of Public Health at the University of Michigan. He received an M.S. in operations research/ systems science, an M.S. in applied statistics and a Ph.D. in management science from Michigan State University. He has published or has articles forthcoming in Decision Sciences, Environmental Health Perspectives and American Journal of Public Health. He is a member of the Decision Sciences Institute and INFORMS.

Soumen Ghosh is an associate professor of operations management in the School of Management, and director of the International Quality Center for Change Leadership at Georgia Institute of Technology. He received his Ph.D. in operations management and M.S. in industrial and systems engineering from The Ohio State University. His research and teaching interests are in the areas of quality management, global aspects of manufacturing and logistics strategy, manufacturing-marketing strategic interface, cellular and flexible manufacturing systems, and manufacturing planning and control. His research has been published in several journals, including Decision Sciences, Journal of Operations Management, International Journal of Production Research, European Journal of Operational Research, and IIE Transactions. He is a member of the Decision Sciences Institute, INFORMS, and the American Society for Quality Control; and serves on the editorial review board of the Joumal of Operations Management. 